\title{
Interactive comment on "Deformation
} characteristics and exploratory data analysis of rainfall-induced rotational landslide: A case study of the Zhutoushan landslide in Nanjing, China" by Weiguo Li et al.

Chia-Ming Lo

ppb428@yahoo.com.tw

Received and published: 15 July 2020

The authors have incorporated the main changes suggested in the revision of the paper. So, I recommend to accept publication.

Interactive comment on Nat. Hazards Earth Syst. Sci. Discuss., https://doi.org/10.5194/nhess- 